\title{
Earthquake forecasting:
}

Small earthquakes show when big ones are more likely

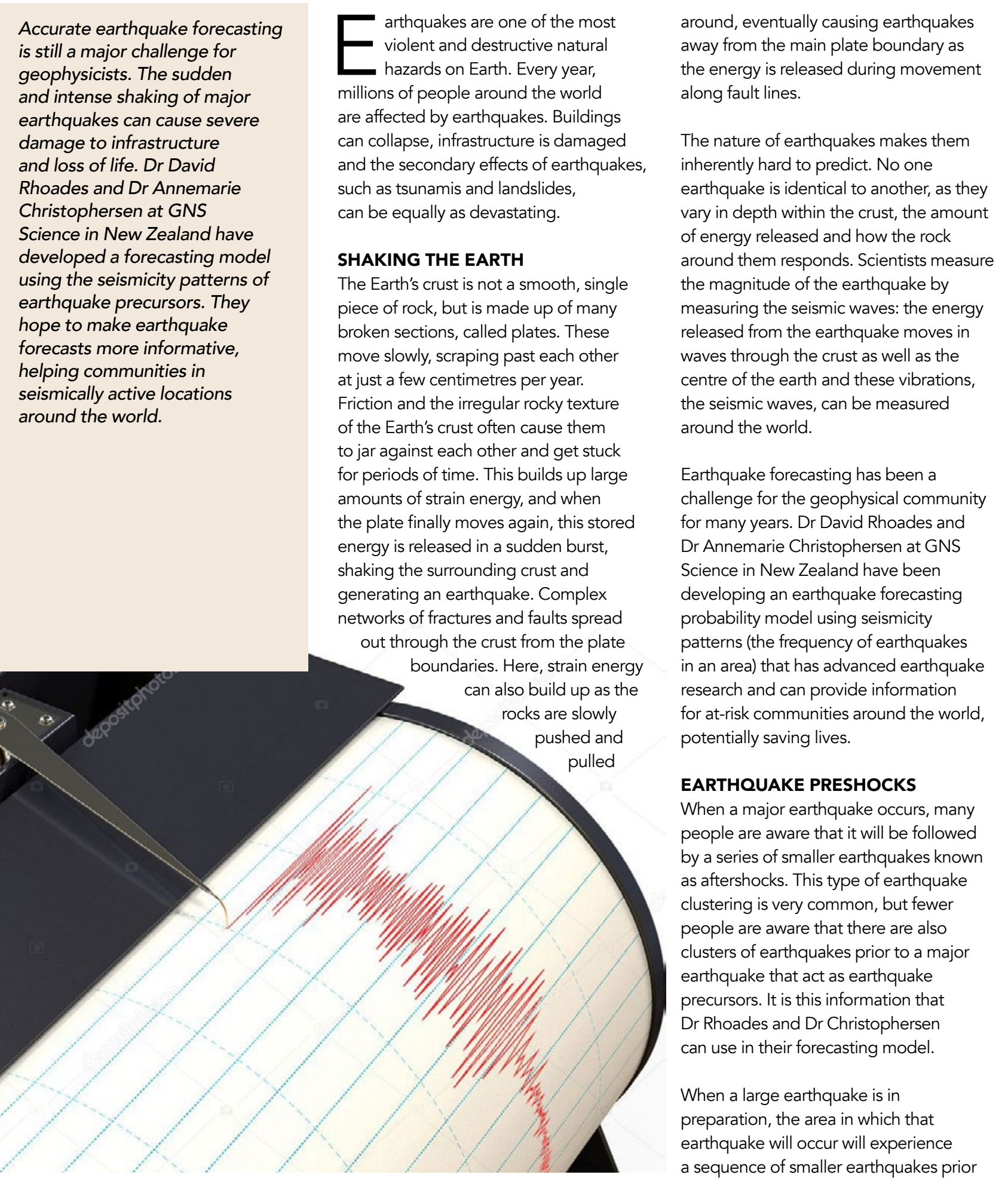

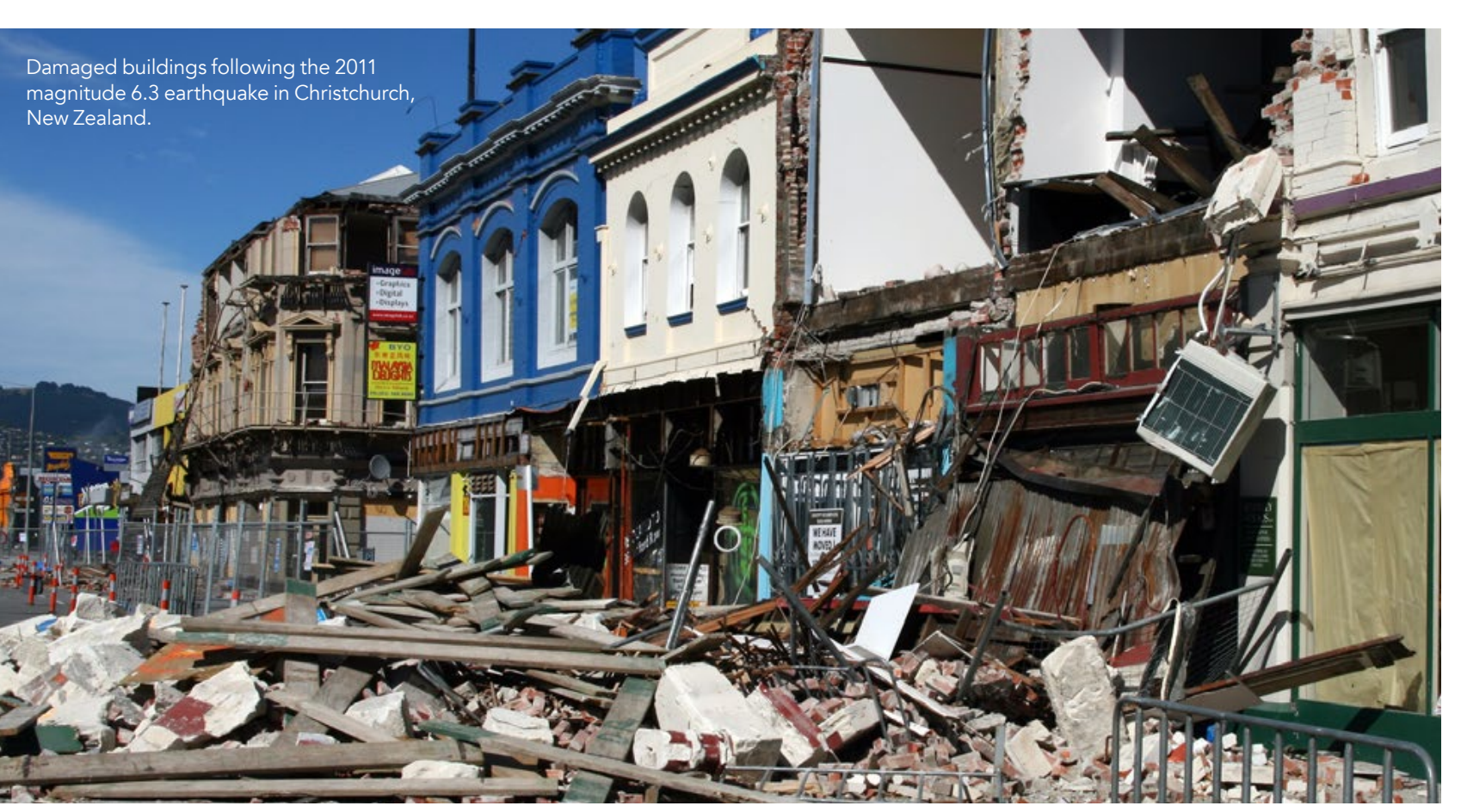

to the event. This clustering of precursory earthquakes can occur over just a few months or over a period of decades prio to the major earthquake. The larger the coming earthquake is, the larger the precursors will be and the longer the period and larger the area occupied by the precursors. This phenomenon is known as the precursory scale increase.

\section{THE EEPAS MODEL}

Dr Rhoades and Dr Christophersen have been working to improve a model for earthquake forecasting based on the precursory-scale-increase phenom The Every Earthquake a Precursor According to Scle (EEAS model uses of the preshocks, the magnitude of the large earthquate and the perod and area occupied by the preshocks to forecast the probability of future large earthquakes within a specific region. The model assumes that every observed earthquake may be a preshock of a larger earthquake to follow. The team can collect information about earthquakes over a defined period to generate an earthquake forecast that gives a likelihood of earthquakes occurring at any future time, location and potential magnitude.

The model was initially developed using data from New Zealand earthquakes. New Zealands location on the boundary Plate means that it expeinces thousands
Clusters of earthquakes prior to a major event act as earthquake precursors.

of earthquakes every year, with at least a hundred of these strong enough to be felt. The model used the data on previous earthquakes to forecast shallow earthquakes with a magnitude greater than 5.75 between 1965 and 2000. By applying it retrospectively to data from New Zealand, it was possible to test the forecasting ability of the EEPAS model.

USING THE EEPAS MODEL

Versions of the EEPAS model have since been applied to earthquake data from Greece and Japan. It has been evaluated by the international Collaboratory for the Study of Earthquake Predictability (CSEP) group who regularly conduct

$\Psi$ predictive scaling relations
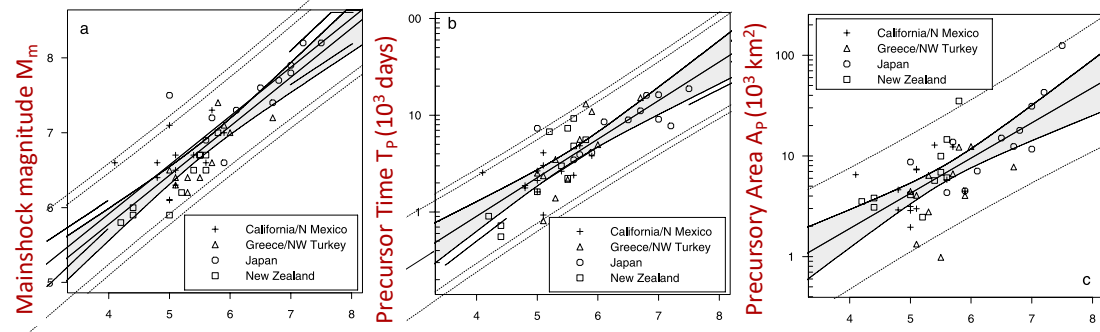
Precursor magnitude Precursor magnitude $M$

$\Psi$ predictive scaling relations between (a) mainshock magnitude $M_{m}$ and precursor magnitude $M_{p} ;(b)$

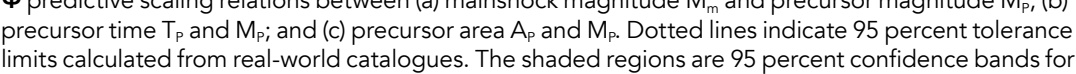




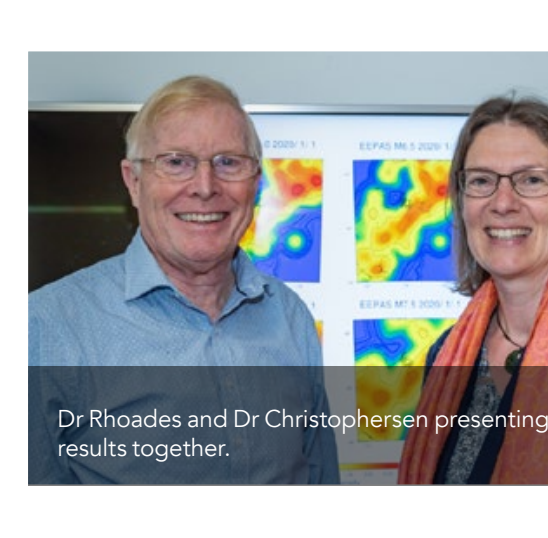

The model was used to inform the rebuilding and planning of infrastructure following these earthquakes where it was required to cover a forecast period of up to 100 years. This provided a new challenge for Dr Rhoades and Dr Christophersen as the EEPAS mod underpredicts the probability of earthquakes when attempting to forecast (a time-lag).

\section{OVERCOMING THE TIME-LAG} In their most recent paper Dr Rhoades and Dr Christophersen compensate for this time lag. The issue is caused by missing data. As the model is required to forecast several years in the data to period. Tut into the model for this earth The 'completeness' of precursoy the magnitude of the major earthqua and the length of the time-lag. The model has two main components: a time-invariant component and a time

EEPAS forecast for 2030
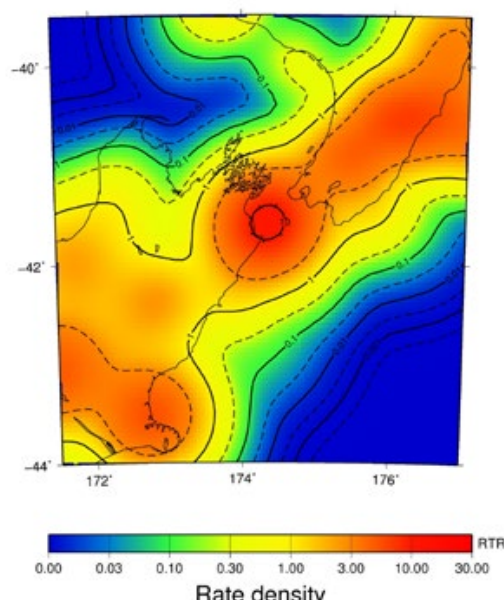

Rate density

Forecast for 2030 and magnitude 7.5 by the
EEPAS Model compensated for the time-lag

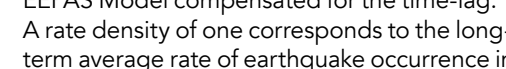
term average rate of eart
the New Zealand region.
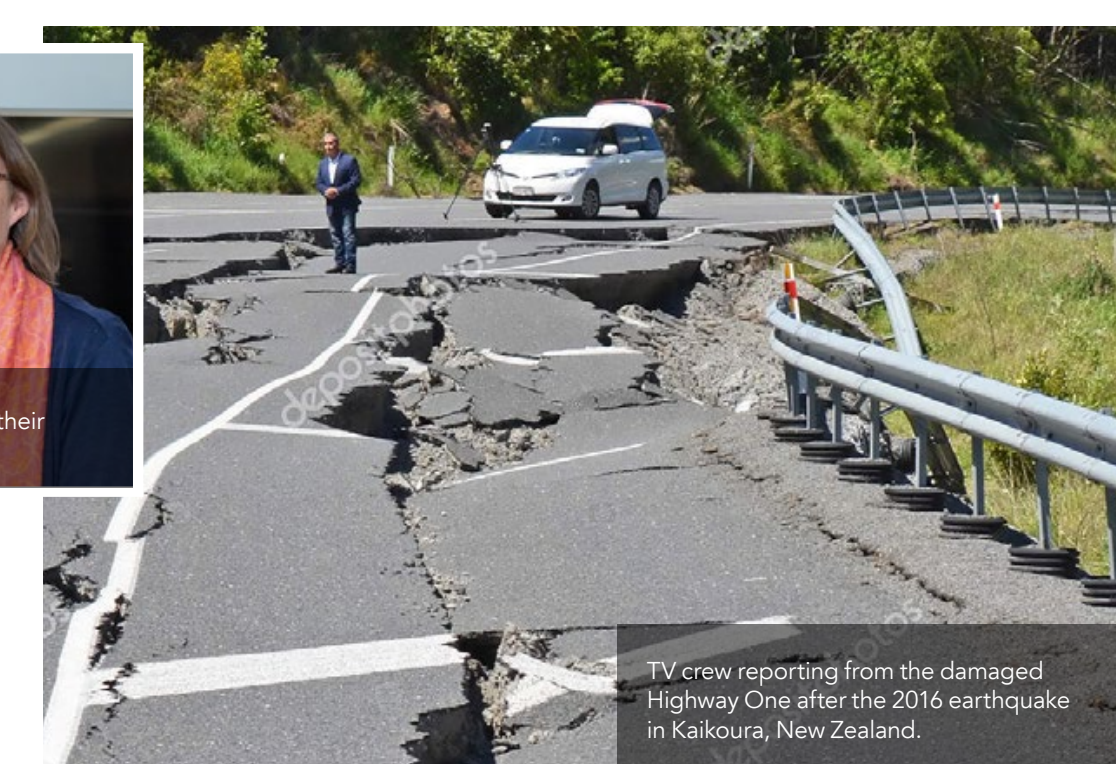

at.

varying component. The team tested
different methods of compensating different methods of compensating for incomplete data, by boosting or the time-varying component.

Ultimately, Dr Rhoades and Dr Christophersen found that a combination of these two methods provided the best results for making forecasts across a time-lag. They again tested the newly models. However, this is not the only mprovement the team hopes to make the model. The physics behind

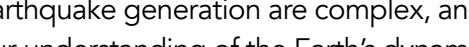
crust is constantly evolving Geophysicists use numerical earthquake simulators to create synthetic earthquake data, allowing in-depth study of many different earthquake scenarios.

The EEPAS model has been applied to earthquake data all over the world, including New Zealand, California, Greece and Japan.

compensated model design using found that the updated model showed a much-improved performance with timelags up to 12 years. The EEPAS model was able to make annual probability forecasts of earthquakes with a magnitud between six and eight on the Richter scale up to the year 2030, based on data on previous earthquakes up to 2018 . Whis the likelihood of an earthquake of this strength remained low, the probability was much higher than in previous years, suggesting central New Zealan may continue to experience more periods until at least 2030 .

\section{THE FUTURE OF EEPAS}

By overcoming the problem of time lags, the EEPAS model continues to
The precursory-scale-increase

of a forthcoming major earthquake,

is also seen within these synthetic

earthquake datasets. Applying the EEPAS

model to this synthetic data will help

geophysicists to understand why this

phenomenon occurs. Additionally, further applying the model to a wide variety its forecasting abilities.

Ultimately, being able to provide more is of real importance to communities who live within seismically active zones. A forecast of when an earthquake migh be made to mitigate the impons to be made to mitigate the impac
Then, where precursor of earthquake data will help to develop accurate forecasts of major earthquakes

\section{Behind the Research \\ David Rhoades

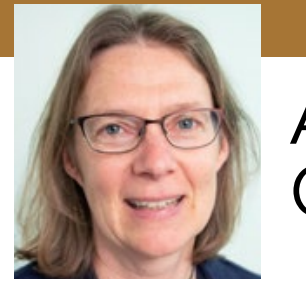 \\ Annemarie Christophersen}

E: d.rhoades@gns.crinz T: +64278859139 (cell), +6445704680 (wk) W: Www.gns.cri.nz
W: https://www.gns.cri.nz/who/staff/1144.html W: https://www.gns.cri.nz/who/staff/2392.html

Research Objectives

Drs Rhoades and Christophersen's work aims to improve the performance of earthquake forecasts.

C)

\section{Detail}

Bio

David Rhoades is a Principal Scientist at GNS Science, New Zealand. $\mathrm{He}$ completed a BSc (Hons) degree at Victoria University of Wellington and MS and PhD degrees in mathematics at the University of Minnesota. He has worked on testable earthquake forecasting models since 1977, beginning with models based on precursory swarms.

and leads the Earthquake Physics the equivalent of a Master's in Physiss at Christian-Albrechts-University, Kiel, Germany, and a PhD in geophysics at Victoria University of Wellington, New Zealand, on the probability of large earthquakes.

Funding

Ministry of Business, Innovation and

Annemarie Christophersen is a senio Platform: Earthquake Commiss scientist with GNS Science, New Zealand

\section{Collaborators}

Frank Evison (1922-2005) as the instigator of this line of research. Matt Gerstenberger (for hybrid Robinson, Keith Richards-Dinger, and Harmony Colella (earthquake simulators) and Sebastian Hainzl (analysis of synthetic and real data). Margaret Low, GNS Science

\section{References}

Rhoades, D.A. \& Christophersen, A. (2019) Timevarying probabilities of earthquake occurrence in compensted for time International, 219, 417-429

Rhoades, D.A. \& Evison, F.F. (2004). Long-range earthquake forecasting with Every Earthquake Precursor According to Scale. Pure and Applied Geophysics, 161, 47-72

Christophersen, A., Rhoades, D.A. \& Colella, H.V. 2017). Precursory seismicity in regions of low strain rate: insights from a physics-based earthquake simulator. Geophysical Journal International, 209 1513-1525

Rhoades, D.A. (2010). Lessons and Questions from Thirty Years of Testing the Precursory Swarm 629-644

\section{Personal Response}

What first sparked your interest in earthquake forecasting? II David: In 1976 I was approached by Professor Frank Evison who had noticed that swarms sometimes precede major swarm earthquakes, the size of the major earthen the size of the between them. He requested statistical help with using swarms to forecast large earthquakes. For several decades we collaborated on testing this precursory swarm hypothesis. Eventually, we realised phenteral model proved more amenable to rigorous testing using the methos of statistical seismology.

Annemarie: I first got interested in earthquakes and plate tectonics when travelling New Zealand in 1996 exploring the beautiful scenery Wellington I met Prof Euan Smith, who had just discussed a possible student project with David Middleton, then the CEO of the New Zealand Earthquake Commission (EOC). EQC was interested in the "duration" of an earthquake for re-insurance purposes, leading to
the topic of my PhD thesis "The probability of a damaging earthquake working on understanding why precursory seismicity occurs. 